\title{
Accelerated increase in plant species richness on mountain summits linked to climate warming
}

Manuel J. Steinbauer ${ }^{1,2}$, John-Arvid Grytnes ${ }^{3}$, Gerald Jurasinski ${ }^{4}$, Aino Kulonen ${ }^{3,5}$, Jonathan Lenoir ${ }^{6}$, Harald Pauli ${ }^{7}$, Christian Rixen ${ }^{5}$, Manuela Winkler ${ }^{7}$, Manfred BardyDurchhalter $^{7}$, Elena Barni ${ }^{8}$, Anne D. Bjorkman ${ }^{1,9,10}$, Frank T. Breiner ${ }^{11,12}$, Sarah Burg ${ }^{5}$, Patryk Czortek $^{13}$, Melissa A. Dawes ${ }^{5,12}$, Anna Delimat ${ }^{14}$, Stefan Dullinger ${ }^{15}$, Brigitta Erschbamer ${ }^{16}$, Vivian A. Felde ${ }^{3}$, Olatz Fernández-Arberas ${ }^{17}$, Kjetil .F. Fossheim ${ }^{3}$, Daniel Gómez-García $^{17}$, Damien Georges ${ }^{1,18}$, Erlend T. Grindrud ${ }^{19}$, Sylvia Haider ${ }^{10,20}$, Siri V. Haugum $^{3}$, Hanne Henriksen ${ }^{19}$, María J. Herreros ${ }^{17}$, Bogdan Jaroszewicz ${ }^{13}$, Francesca Jaroszynska $^{3,21}$, Robert Kanka ${ }^{22}$, Jutta Kapfer ${ }^{23}$, Kari Klanderud ${ }^{19}$, Ingolf Kühn²,20,10, Andrea Lamprecht' ${ }^{7}$, Magali Matteodo ${ }^{5,25}$, Umberto Morra di Cella ${ }^{26}$, Signe Normand ${ }^{2}$, Arvid Odland ${ }^{27}$, Siri L. Olsen ${ }^{28}$, Sara Palacio ${ }^{17}$, Martina Petey ${ }^{26}$, Veronika Piscová ${ }^{22}$, Blazena Sedlakova $^{29}$, Klaus Steinbauer ${ }^{7}$, Veronika Stöckli ${ }^{5,30}$, Jens-Christian Svenning ${ }^{1,31}$, Guido Teppa ${ }^{8}$, Jean-Paul Theurillat ${ }^{32,33}$, Pascal Vittoz ${ }^{25}$, Sarah J. Woodin ${ }^{21}$, Niklaus E. Zimmermann ${ }^{12,34}$, Sonja Wipf ${ }^{5}$

${ }^{1}$ Section for Ecoinformatics and Biodiversity, Department of Bioscience, Aarhus University, 8000 Aarhus C, Denmark.

${ }^{2}$ GeoZentrum Nordbayern, Department of Geography and Geosciences, Friedrich-Alexander University of Erlangen-Nürnberg (FAU), Loewenichstr. 28, 91054 Erlangen, Germany

${ }^{3}$ Department of Biology, University of Bergen, PO Box 7803, 5020 Bergen, Norway.

${ }^{4}$ Landscape Ecology, University of Rostock, Justus-von-Liebig-Weg 6, 18059 Rostock, Germany.

${ }^{5}$ WSL Institute for Snow and Avalanche Research SLF, Davos, Switzerland, Flüelastrasse 11, 7260 Davos Dorf, Switzerland.

${ }^{6}$ UR «Ecologie et Dynamique des Systèmes Anthropisés» (EDYSAN, FRE 3498 CNRSUPJV), Université de Picardie Jules Verne, 1 Rue des Louvels, FR-80037 Amiens Cedex 1, France.

${ }^{7}$ GLORIA coordination, Institute for Interdisciplinary Mountain Research at the Austrian Academy of Sciences (ÖAW-IGF) \& Center of Global Change and Sustainability at the University of Natural Resources and Life Sciences (BOKU-ZgWN), Silbergasse 30/3, 1190 Vienna, Austria.

${ }^{8}$ Department of Life Sciences and Systems Biology, University of Torino, Viale Mattioli 25, 10125 Torino, Italy.

${ }^{9}$ School of GeoSciences, University of Edinburgh, The King's Buildings, Alexander Crum Brown Road, Edinburgh EH9 3FF, UK

${ }^{10}$ German Centre for Integrative Biodiversity Research (iDiv) Halle-Jena-Leipzig, Deutscher Platz 5e, 04103 Leipzig, Germany.

${ }^{11}$ Department of Ecology and Evolution, University of Lausanne, Le Biophore, 1015 Lausanne, Switzerland.

${ }^{12}$ Swiss Federal Institute for Forest, Snow and Landscape Research (WSL), Zürcherstrasse 111, 8093 Birmensdorf, Switzerland.

${ }^{13}$ Białowieża Geobotanical Station, Faculty of Biology, University of Warsaw, Sportowa 19, 17-230 Biatowieża, Poland.

${ }^{14}$ W. Szafer Institute of Botany, Polish Academy of Sciences, Lubicz 46, 31-512 Kraków, Poland. 
${ }^{15}$ Department of Botany and Biodiversity Research, University of Vienna, Rennweg 14, 1030 Vienna, Austria.

${ }^{16}$ Institute of Botany, University of Innsbruck, Sternwartestr. 15, A-6020 Innsbruck, Austria

${ }^{17}$ Instituto Pirenaico de Ecología (IPE-CSIC), Avda. Nuestra Señora de la Victoria, 16, 22700 Jaca, Huesca, Spain.

${ }^{18}$ International Agency for Research on Cancer, 150 cours Albert Thomas, 69003 Lyon, France.

${ }^{19}$ Faculty of Environmental Sciences and Natural Resource Management, Norwegian University of Life Sciences, NO-1432 Ås, Norway.

${ }^{20}$ Martin Luther University Halle-Wittenberg, Institute of Biology/Geobotany and Botanical Garden, Am Kirchtor 1, 06108 Halle, Germany

${ }^{21}$ School of Biological Sciences, University of Aberdeen, Aberdeen, AB24 3UU, UK.

${ }^{22}$ Institute of Landscape Ecology, Slovak Academy of Sciences, Štefánikova 3, 81499 Bratislava, Slovakia.

${ }^{23}$ Department of Landscape Monitoring, Norwegian Institute of Bioeconomy Research, Holtvegen 66, 9016 Tromsø, Norway.

${ }^{24}$ Department for Community Ecology, Helmholtz Centre for Environmental Research - UFZ, Theodor-Lieser-Str. 4, 01260 Halle, Germany.

${ }^{25}$ Institute of Earth Surface Dynamics, University of Lausanne, Le Geopolis, 1015 Lausanne, Switzerland.

${ }^{26}$ Environmental Protection Agency of Aosta Valley, Loc. Grande Charrière 44, 11020 SaintChristophe, Italy.

${ }^{27}$ Department of Natural Sciences and Environmental Health, University College of Southeast Norway, 3800 Bø, Norway.

${ }^{28}$ Norwegian Institute for Nature Research, Gaustadalléen 21, 0349 Oslo, Norway.

${ }^{29}$ Administration of the Tatra National Park, 05921 SVIT, ul. Kpt. Nálepku 2.

${ }^{30}$ Bergwelten 21 AG, 7270 Davos Platz, Switzerland.

${ }^{31}$ Center for Biodiversity Dynamics in a Changing World (BIOCHANGE), Aarhus University, Ny Munkegade 114, Aarhus, Denmark

${ }^{32}$ Centre Alpien de Phytogéographie, Fondation J.-M. Aubert, 1938 Champex-Lac, Switzerland

${ }^{33}$ Section of Biology, University of Geneva, 1292 Chambésy, Switzerland.

${ }^{34}$ Department of Environmental Systems Science, Swiss Federal Institute of Technology ETH, 8092 Zurich, Switzerland. 
Globally accelerating trends in societal development and human environmental impacts since the mid-20th century ${ }^{1-7}$ are known as the Great Acceleration and discussed as a key indicator of the onset of the Anthropocene ${ }^{6}$. While reports on ecological responses (e.g. species range shifts or local extinctions) to the Great Acceleration are multiplying ${ }^{8,9}$, it is unknown whether such biotic responses are undergoing a similar acceleration over time. This knowledge gap stems from the limited availability of time series data on biodiversity changes across large temporal and geographical extents. Here, we use a unique dataset of repeated plant surveys from 302 mountain summits across Europe, spanning 145 years of observation, to assess the temporal trajectory of mountain biodiversity changes as a globally coherent imprint of the Anthropocene. We find a continent-wide acceleration in the rate of plant species richness increase, with five times higher species enrichment over the last decade compared to fifty years ago. This acceleration is strikingly synchronized with accelerated global warming, and not linked to alternative global change drivers. The accelerating increases in species richness on mountain summits across this broad spatial extent demonstrate that acceleration in climate-induced biotic changes is occurring even at remote places on Earth, with potentially far-ranging consequences not only for biodiversity, but also for ecosystem functioning and services. 
Mountains are particularly sensitive to ecological change and are experiencing some

of the highest rates of warming under anthropogenic climate change ${ }^{10,11}$. Numerous reports of species re-distribution towards the summits $8,12-14$ and warming-induced changes in biodiversity on summits ${ }^{13,15,16}$ suggest that mountain biota are highly sensitive to increasing temperatures ${ }^{17}$. The current accelerating trends in temperature increase ${ }^{1,6}$ should therefore also affect the velocity of changes observed for mountain biota. Appropriate empirical assessments of the rate of change in the velocity of ecological responses (biodiversity and ecosystem trajectories) to accelerated global warming require long-term resurveys (e.g. time series) of species communities, but these are scarce and localized. Mountain summits are especially suited for long-term studies of biotic responses to environmental changes because they represent natural permanent study sites that are easy to re-locate over time ${ }^{18,19}$, thus allowing to record reliable time series. By repeatedly resurveying alpine plant communities on 302 European mountain summits dating back as far as 1871, we generated time series for century-scale and continent-wide biodiversity dynamics to assess potential acceleration trends in plant diversity dynamics (Fig. 1). Using these time series data, we tested whether the recent acceleration of climate change is driving a similarly accelerating change in species richness on mountain summits across the continent.

Here we show that plant species richness has strongly increased over the past 145 years on the vast majority (87\%) of Europe's summits (generalized linear mixed effects model: $\mathrm{p}<0.001$; Fig. 2; Extended Data Table 1) and the increase has accelerated in the most recent years. This trend is consistent across all nine covered geographical regions, with no single region showing the opposite pattern. Across all summits, this increase in plant species richness has accelerated over time (linear mixed effects models: $\mathrm{p}<0.001$; Fig. 3; Extended Data Table 2), and the acceleration has been particularly pronounced during the last 20-30 years (Figs 2 and 3). Fifty years ago (1957 to 1966), the rate of increase in species numbers averaged 1.1 species per decade (Fig. 3), while during the last decade (2007 to 2016) the summits gained 5.4 additional species on average (Fig. 3). There is a positive relationship 
between the magnitude of increase in plant species richness and the rate of warming across all 302 time series (linear mixed effects models: $\mathrm{p}<0.001$; Fig. 4a and Extended Data Figure 2a; Extended Data Table 3). The temporal and spatial congruence between the velocity of climate change and the species accumulation rates on mountain summits across Europe corroborates the hypothesis that warming is the primary driver of locally observed upward shifts of species ranges in mountains (Fig. 2) ${ }^{12,13,20}$ and their recent acceleration ${ }^{16,21}$. Our findings thus align with those of shorter-term studies demonstrating plant community thermophilization ${ }^{15,17}$ and range shifts driven by warming?.

The observed relationship between temperature change and species richness change over the past 145 years is consistent across all nine regions. Changes in precipitation and nitrogen deposition also correlate with species richness changes regionally, but the direction and magnitude of these effects differ strongly between regions (Extended Data Figure 2b, c). While precipitation change $(\Delta \mathrm{P} /$ year) has a moderate (positive) effect on species richness trends across Europe (Extended Data Table 3; Fig. 4b, c), its effect is not consistent and significant across all analysed regions (Extended Data Table 6; Extended Data Figure 2b) and is minor compared to the effect of temperature change ( $\Delta \mathrm{T} / \mathrm{year}$; Extended Data Table 4 and 6). Changes in grazing and tourism could also affect changes in plant species richness on summits $^{21}$. Local studies suggest that grazing ${ }^{22}$ and frequent disturbance by tourists ${ }^{15}$ may suppress the elevational advance of alpine plants in response to warming in mountains. While quantification is challenging, locally declining levels in domestic livestock are often in synchrony with recovery of wild ungulate populations. Hiking tourism increased on some summits, but intensities vary strongly. Land-use changes may thus explain parts of the local variation in species richness trends, however, they vary greatly within and between regions. Without a consistent impact on species re-distribution, it is unlikely that changes in grazing and tourism can account for the consistent, continent-wide increase in plant species richness evident in our data. 
Some previous observations suggest that upslope species migration in mountains

occurs almost in synchrony with climate warming ${ }^{17}$, while other studies indicate strong lags in dispersal, establishment, and extinction expected for many alpine plant species ${ }^{23,24}$. We systematically tested for time-lags (up to 10 years) in species richness increase following climate changes, but found that time-lags did not significantly improve the explanatory power of our models (Extended Data Table 5). This finding suggests that increases in species richness on European summits are a direct and immediate response to climate warming (see also Fig. 2) and, thus, can be expected to further accelerate as climate warming continues to accelerate ${ }^{1}$. Because we focus on the average trend, and by not accounting for non-colonizing lower-altitude species, we cannot, however, exclude the possibility that only a fraction of species responded quickly to climate change, thus creating the observed relationship, while an unknown number of species lags behind the change in climate. Our observations may, therefore, underestimate the expected long-term species turnover on summits.

The accelerated increase of species richness on mountain summits likely results from an upward shift of the upper range limits of an increasing number of species. Trait analyses indeed show that new colonizers exhibit growth strategies characterizing lower elevations, having larger size $(\mathrm{p}<0.001)$, higher specific leaf area $(\mathrm{p}<0.01)$ and a general association with warmer temperatures ( $<<0.001$; Extended Data Table 7). Ultimately, the lower range limits of species will also shift upwards, but these limits are often determined and changed by biotic interactions and are, therefore, only indirectly related to temperature ${ }^{25}$. As more species establish at high-elevation sites, local extinctions will likely occur due to competitive replacement of slow-growing, stress-tolerant alpine species by more vigorous generalists that benefit from warming, rather than by direct adverse effects of warming on the summit species $^{26}$. However, competitive replacement of resident species requires that colonizers build up sufficiently large populations. Local extinctions should hence follow colonization with a time-lag. Consequently, accelerating plant species richness increases would be a transient phenomenon which hides the accumulation of a so-called extinction $\operatorname{debt}^{23,27}$. The relaxation 
time until this debt is paid off is likely characterized by continuous shifts in abundance ratios which may serve as sensitive early-warning signals of upcoming extinctions ${ }^{15}$. The length of the relaxation time likely depends on factors such as the longevity of high-elevation species, plant clonal abilities, and the local microhabitat diversity, supporting the persistence of coldclimate microrefugia for high-alpine species ${ }^{28,29}$. Although these processes, along with others such as the species' intrinsic ability to tolerate changing climates, may buffer local extinctions, rapid loss of alpine-nival species may occur under accelerated climate warming. Additionally, if major changes and extinctions in alpine systems are not gradual, but initiated by threshold-like dynamics (e.g. shrub and tree encroachment), critical tipping points may be approached with increasing speed under accelerated climate warming.

Our results underline the link between accelerating climate warming and species richness change in mountains. We thus provide a particularly compelling example of the human-driven impact on terrestrial biota that is highly consistent with the recently reported Great Acceleration in Earth system trends in the Anthropocene and strikingly synchronous with the recent accelerating trends observed in many socio-economic indicators ${ }^{6}$. The observed acceleration of biodiversity change in mountain ecosystems highlights the rapid and widespread consequences of human activities on the biosphere, with important consequences for ecosystem functioning, human well-being, and the dynamics of climate change ${ }^{30}$.

\section{References:}

1. Smith, S. J., Edmonds, J., Hartin, C. A., Mundra, A. \& Calvin, K. Near-term acceleration in the rate of temperature change. Nat. Clim. Change. 5, 333-336 (2015).

2. Comiso, J.C., Parkinson, C.L., Gersten, R. \& Stock, L. Accelerated decline in the Arctic sea ice cover. Geophys. Res. Lett. 35, L01703 (2008).

3. Kintisch, E. Sea ice retreat said to accelerate Greenland melting. Science 352, 1377 (2016). 
4. Hughes, T.P. et al. Global warming and recurrent mass bleaching of corals. Nature 543, 373-377 (2017).

5. Hollesen, J., Matthiesen, H., Møller, A.B. \& Elberling, B. Permafrost thawing in organic Arctic soils accelerated by ground heat production. Nat. Clim. Change. 5, 574-578 (2015).

6. Steffen, W., Broadgate, W., Deutsch, L., Gaffney, O. \& Ludwig, C. The trajectory of the Anthropocene: The Great Acceleration. The Anthropocene Review 2, 81 - 98 (2015).

7. Alstad, A.O. et al., The pace of plant community change is accelerating in remnant prairies. Science Advances 2, e1500975 (2016).

8. Chen, I.C., Hill, J.K., Ohlemuller, R., Roy, D.B. \& Thomas, C.D. Rapid range shifts of species associated with high levels of climate warming. Science 333, 1024-1026 (2011).

9. Wiens, J.J. Climate-related local extinctions are already widespread among plant and animal species. PLoS Biology 14, e2001104 (2016).

10. Gobiet, A. et al. 21st century climate change in the European Alps - A review. Sci. Total Environ. 493, 1138-1151 (2014).

11. Pepin, N. et al. Elevation-dependent warming in mountain regions of the world. Nat. Clim. Change. 5, 424-430 (2015).

12. Lenoir, J., Gégout, J.-C., Marquet, P.A., de Ruffray, P. \& Brisse, H. A significant upward shift in plant species optimum elevation during the 20th century. Science 320, 1768-1771 (2008).

13. Pauli, H. et al. Recent plant diversity changes on Europe's mountain summits. Science 336, 353-355 (2012).

14. Grytnes, J.-A. et al. Identifying driving factors behind observed species range shifts on European mountains. Global Ecol. Biogeogr. 23, 876-884 (2014).

15. Gottfried, M. et al. Continent-wide response of mountain vegetation to climate change. Nat. Clim. Change. 2, 111-115 (2012). 
16. Wipf, S., Stöckli, V., Herz, K. \& Rixen, C. The oldest monitoring site of the Alps revisited: Accelerated increase in plant species richness on Piz Linard summit since 1835. Plant Ecol. Divers. 6, 447-455 (2013).

17. Bertrand, R. et al. Changes in plant community composition lag behind climate warming in lowland forests. Nature 479, 517-520 (2011).

18. Stöckli, V., Wipf, S., Nilsson, C. \& Rixen, C. Using historical plant surveys to track biodiverstiy on mountain summits. Plant Ecol. Divers. 4, 415-425 (2012).

19. Verheyen, K. et al. Combining biodiversity resurveys across regions to advance global change research. BioScience 67, 73-83 (2017).

20. Odland, A., Høitomt, T. \& Olsen, S.L. Increasing vascular plant richness on 13 high mountain summits in Southern Norway since the early 1970s. Arct. Antarct. Alp. Res. 42, 458-470 (2010).

21. Walther, G.-R., Beißner, S. \& Burga C.A. Trends in the upward shift of alpine plants. J. Veg. Sci. 16, 541-548 (2005).

22. Speed, J.D.M., Austrheim, G., Hester, A.J. \& Mysterud A. Elevational advance of alpine plant communities is buffered by herbivory. J. Veg. Sci. 23, 617-625 (2012).

23. Dullinger, S. et al. Extinction debt of high-mountain plants under twenty-first-century climate change. Nat. Clim. Change. 2, 619-622 (2012).

24. Hülber, K. et al. Uncertainty in predicting range dynamics of endemic alpine plants under climate warming. Glob. Change Biol. 22, 2608-2619 (2016).

25. Vetaas, O.R. Realized and potential climate niches: a comparison of four Rhododendron tree species. J. Biogeogr. 29, 545-554 (2002).

26. Alexander, J.M., Diez, J.M. \& Levine, J.M. Novel competitors shape species’ responses to climate change. Nature 525, 515-518 (2015).

27. Cotto, O. et al. A dynamic eco-evolutionary model predicts slow response of alpine plants to climate warming. Nature Communications 8, 9 (2017).

28. Scherrer, D. \& Körner, C. Topographically controlled thermal-habitat differentiation buffers alpine plant diversity against climate warming. J. Biogeogr. 38, 406-416 (2011). 
29. Winkler, M. et al. The rich sides of mountain summits - a pan-European view on aspect preferences of alpine plants. J. Biogeogr. 43, 2261-2273 (2016).

30. Pecl, G.T. et al. Biodiversity redistribution under climate change: Impacts on ecosystems and human well-being, Science 355, eaai9214 (2017). 
Supplementary Information is linked to the online version of the paper at www.nature.com/nature.

Acknowledgments For their support with the field work, we particularly thank Jessica Wells Abbott, Debora Barolin, John Birks, Anders Björken, Cajsa Björken, Sondre Dahle, Uwe Deppe, Guy Dussassois, José Vicente Ferrández, Thomas Gassner, Sara Giovanettina, Federico Giuntoli, Øystein Lunde Heggebø, Kristina Herz, Anita Jost, Katharina Kallnik, Walter Kapfer, Therese Kronstad, Håvard Laukeland, Sophie Nießner, Mikael Olson, Philippe Roux-Fouillet, Katrina Schofield, Michael Suen, Dan Watson, Jakub Zaremba and many other scientists, students and helpers. We are further very thankful for field work and data originating from the GLORIA network (published in Pauli et al. 2012, Science 336) including contributions by Peter Barančok, José Luis Benito Alonso, Martin Camenisch, Gheorghe Coldea, Jan Dick, Michael Gottfried, Georg Grabherr, Jarle Inge Holten, Jozef Kollár, Per Larsson, Martin Mallaun, Ottar Michelsen, Ulf Molau, Mihai Pușcaș, Peter Unterluggauer, Luis Villar, Gian-Reto Walther and a large number of further scientists and helpers. We also would like to thank Cathy Jenks for linguistic support.

MJS was supported by the Danish Carlsbergfondet (CF14-0148) as well as the EU's Marie Sklodowska-Curie action (grant 707491). CR, VS, and SW were supported by the Velux Foundation, and together with J-PT and PV, by the Swiss Federal Office for the Environment (FOEN). AK was supported by the Swiss National Science foundation (grant 31003A_144011) and by Basler Stiftung für biologische Forschung. JK was supported by the Fram Centre project 362202 and together with J-AG, PC and BJ received funding from the Polish-Norwegian Research Programme operated by the National Centre for Research and Development under the Norwegian Financial Mechanism 2009-2014 in the frame of Project Contract No. Pol-Nor/196829/87/2013. OFA, MJH and SP were supported by the Instituto de Estudios Altoaragoneses (Huesca, Spain). SD was supported by the Austrian Climate Research Programme (ACRP, project 368575: DISEQU-ALP). FJ was supported by the Botanical Society of Britain \& Irland and the Alpine Garden Society. MJH was supported by a Felix de Azara research grant (IBERSUMIT project, DPH, Spain). RK was supported by 
grant project APVV 0866-12. SN was supported by the Villum foundation's Young Investigator Programme (VKR023456). SP was funded by a Ramón y Cajal fellowship (RYC-2013-14164, Ministerio de Economía y Competitividad, Spain). J-CS was supported by the European Research Council (ERC-2012-StG-310886-HISTFUNC) and also considers this work a contribution to his VILLUM Investigator project (VILLUM FONDEN grant 16549). SW was supported by WSL internal grants (201307N0678) and, together with SB, FJ, and MJH by the Swiss Botanical Society Alpine Flower Fund. A workshop for the integration of different resurvey data across Europe and the development of first analytical approaches was supported by sDiv, the Synthesis Centre of iDiv (DFG FZT 118).

Author Contributions SW, MJS, J-AG, GJ, AK, CR, AB, SH, JK, KK, IK, JL, SN, HP, PV and MW elaborated the concept of the manuscript; AK, SW, MB-D, HP, CR, PV and MW organized and harmonized data, MJS implemented the data analyses supported by other authors, particularly SW, J-AG, JL, SD and DG; EB, SB, FB, PC, MAD, AD, BE, VAF, OFA, KF-F, DG-G, ETG, J-AG, SVH, HH, CH, BJ, FJ, RK, KK, JK, AL, MM, UM, AO, SLO, SP, HP, MP, VP, BS, KS, VS, CR, GT, J-PT, PV and SW contributed data. MJS led the manuscript writing, with contributions from all authors.

Data and code availability Data and R code is freely available via the corresponding authors (MJS or SW).

Author Information Reprints and permissions information is available at www.nature.com/reprints. The authors declare no competing financial interests. Readers are welcome to comment on the online version of the paper. Correspondence and requests for materials should be addressed to MJS (steinbauer@bios.au.dk) or SW (sonja.wipf@slf.ch). 


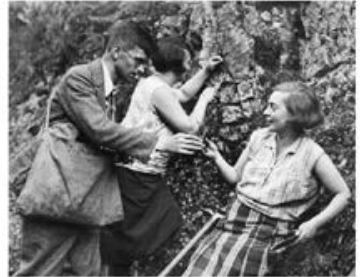

Above: Bogumil Pawlowski (1898-1971)

Left: Pawlowski's herbarium

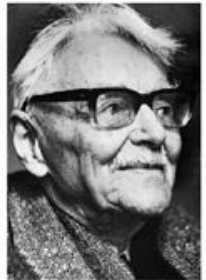

Josias BraunBlanquet

(1884-1980)

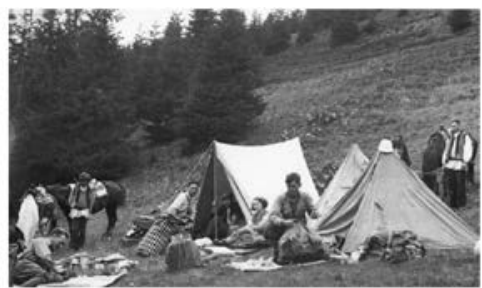

Botanists expedition (Pawlowski)
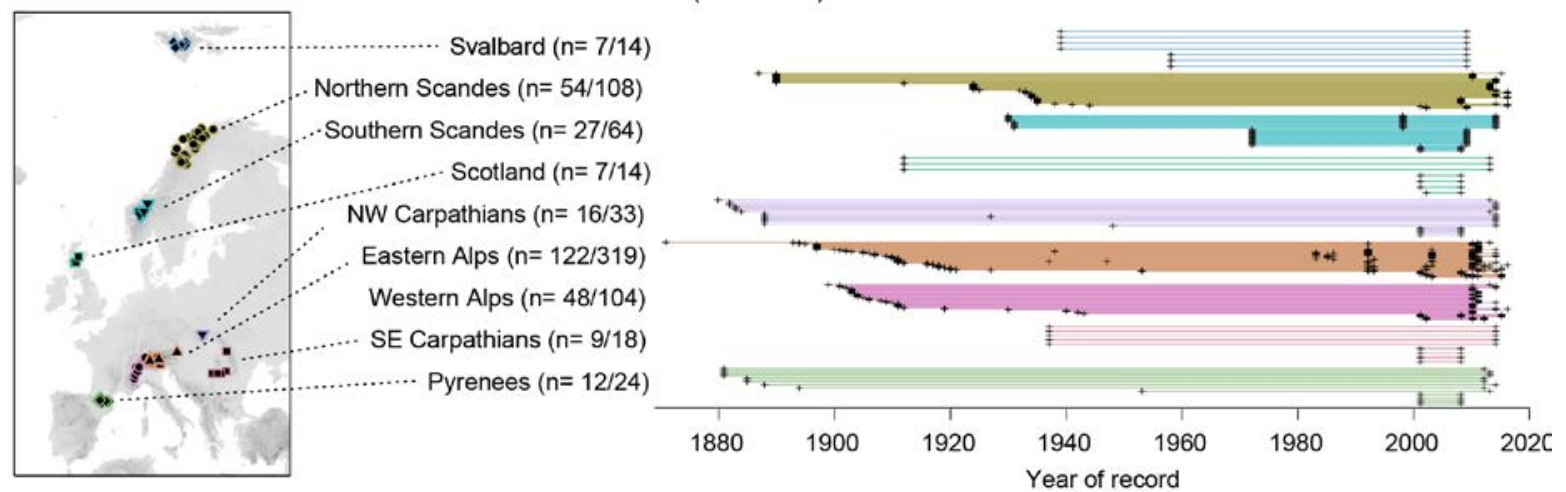

Figure 1 | The study is based on 698 surveys from 302 summits in nine mountain regions across Europe dating back to 1871. Each sampled summit is indicated by one line, with black crosses indicating survey dates. The historical surveys were often conducted by leading pioneers in vegetation ecology in Europe (B. Pawlowski, J. Braun-Blanquet, E. Rübel, E. Du Rietz etc.). Numbers in brackets beside the region names indicate the number of summits/surveys. Picture references for Pawlowski (Zemanek, 2012, Florist. Geobot. Polon.), Braun-Blanquet (Ellenberg 1982, doi 10.1111/j.1438-8677.1982.tb02874.x) and Rübel (ETHBibliothek Zürich, doi 10.3932/ethz-a-000073833). 


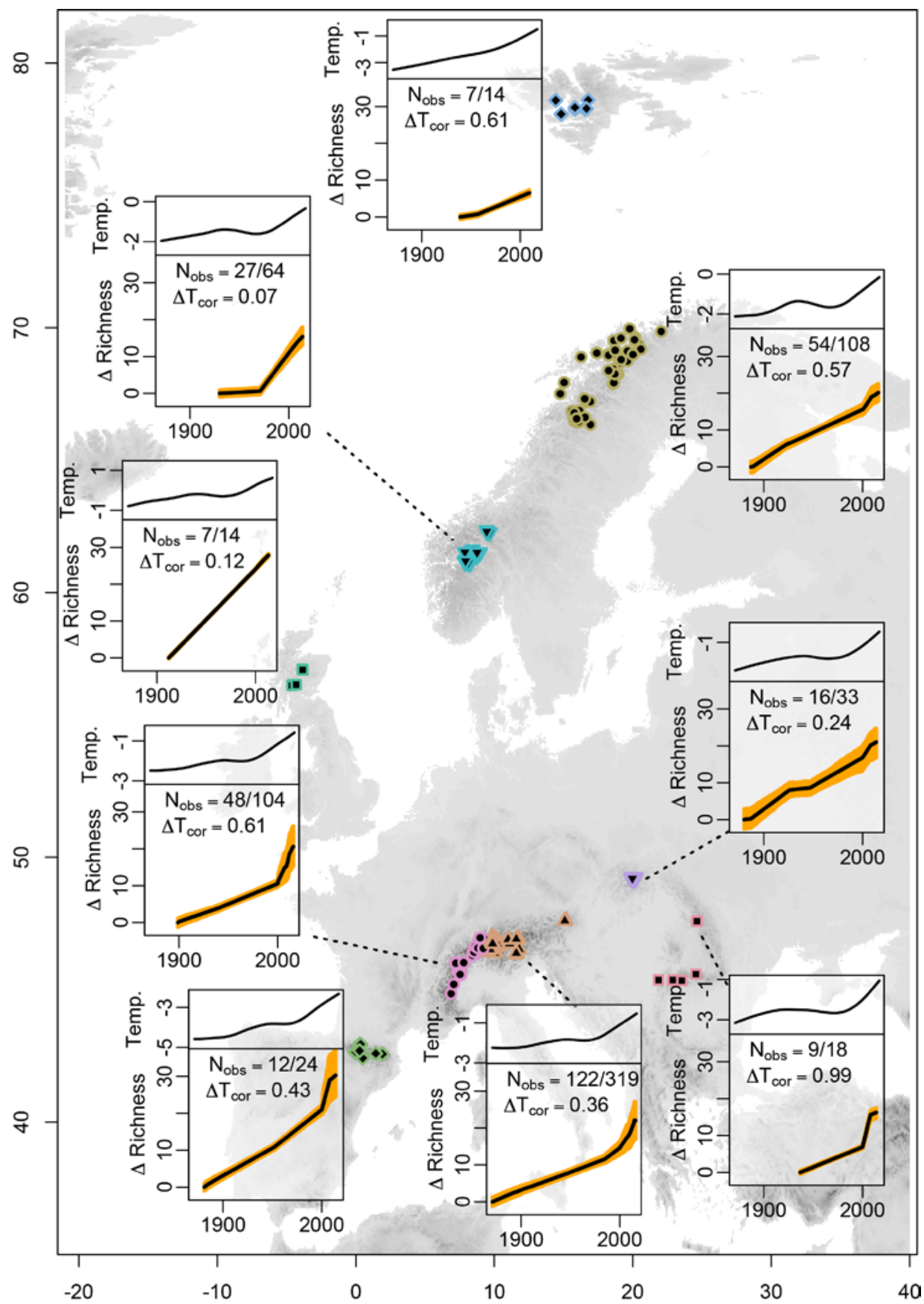

Figure 2 | Average species richness change (in species numbers) on mountain summits over time (lower part of panels) compared to mean annual temperature over time (upper part of panels). " $\mathrm{N}_{\text {obs" }}$ indicates the number of summits/surveys within the mountain region providing data for the respective panel. Correlation between rate of change in species richness and rate of change in temperature $\left(\Delta \mathrm{T}_{\text {cor }}\right)$ is positive for all mountain regions (see also Extended Data Figure 2a). Orange shading marks the $5^{\text {th }}$ and $95^{\text {th }}$ percentiles of the resulting richness change values from a bootstrapping approach across all summits in one region; see Extended Data Figure 1 for methodological details. 


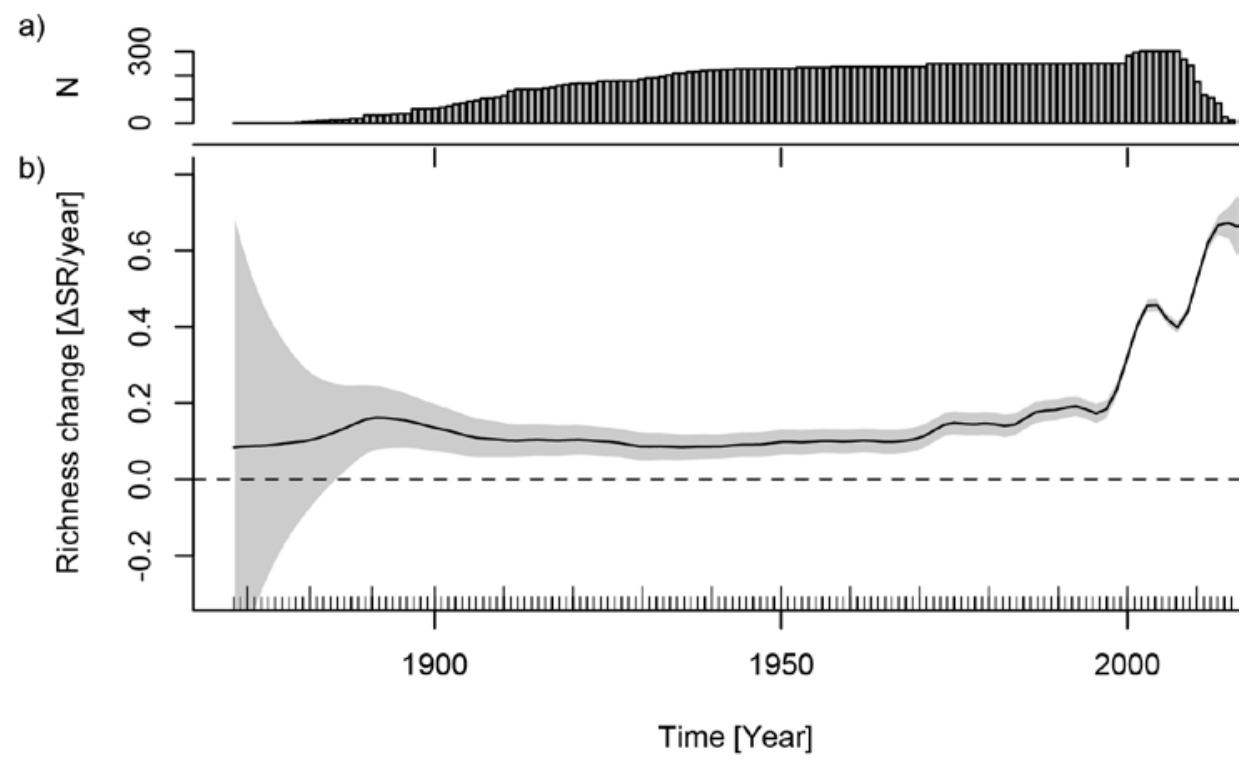

Figure 3 | Rate of species richness change over time (black line, b). Positive values indicate an increase in species richness on summits and negative values indicate a decrease. Rates $\left(\Delta \mathrm{SR} /\right.$ year $\left.=\left(\mathrm{SR}_{\mathrm{t}_{2}}-\mathrm{SR}_{\mathrm{t} 1}\right) /\left(\mathrm{t}_{2}-\mathrm{t}_{1}\right)\right)[\mathrm{SR}=$ species richness, $\mathrm{t}=$ time $]$ were averaged across all summits and inversely weighted by the number of years between observations $\left(t_{2}-t_{1}\right)$ to account for temporal resolution as a longer period between surveys might mask short-term fluctuations. The black line interpolates across all summits with a generalized additive (spline) smooth model (R package mgcv version 1.8-17, the smooth term $(\mathrm{k}=50)$ was chosen to allow enough degrees of freedom to closely represent the underlying pattern). The shaded grey area represents \pm 1 standard error around the mean value (black solid line). a) The histogram at the top of the figure indicates the number of slope parameters per year $(\mathrm{N}$; comparisons of earlier survey and later sampled resurvey) that support the line graph. 

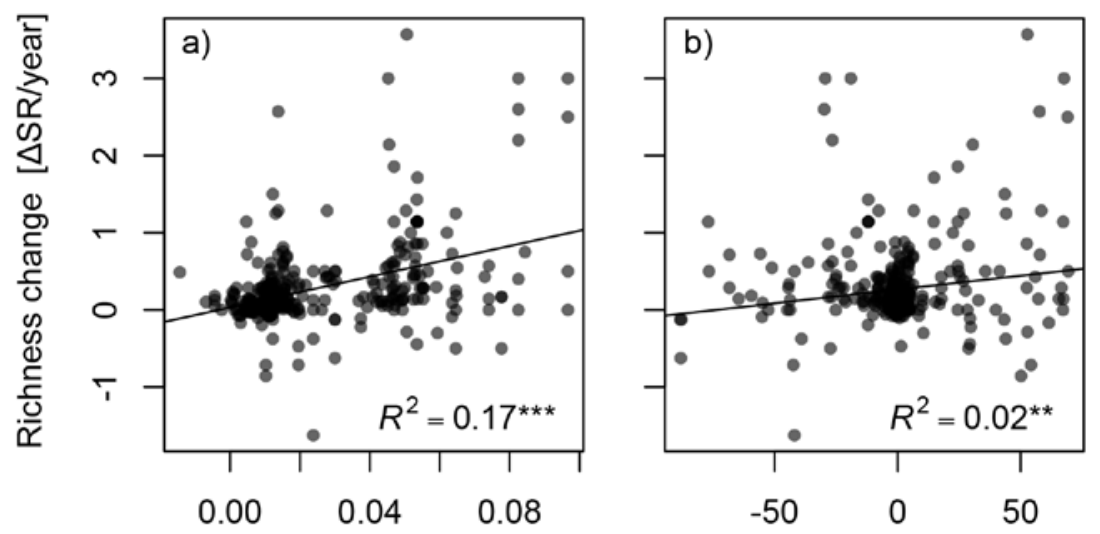

Temperature change $\left[{ }^{\circ} \mathrm{C} /\right.$ year $]$

Precipitation change [mm/year]

Figure 4 | Rate of species richness change $\left(\Delta \mathrm{SR} /\right.$ year $\left.=\left(\mathrm{SR}_{\mathrm{t} 2}-\mathrm{SR}_{\mathrm{t} 1}\right) /\left(\mathrm{t}_{2}-\mathrm{t}_{1}\right)\right)$ related to the rate of: a) temperature change; and b) precipitation change across all sampled mountains in Europe. Note that this pattern differs considerably among regions (see Extended Data Figure 2 for more details at the regional level). Dots are semitransparent, with darker symbols indicating overlapping points. Trend lines and $\mathrm{R}^{2}$ values are based on univariate linear regressions and significance, indicated by stars, is based on F-statistics (see text and Extended Data Table 3 for multivariate analysis). The relationship between change in species richness and accumulated nitrogen (not shown) is not significant, because nitrogen deposition varies strongly across Europe whereas the change of species richness shows the same trend across the continent. See text and methods section for more detailed analyses with generalized mixed effects offset models including regional differences. 


\section{METHODS}

Vegetation resurveys on European mountain summits. Precise relocation of vegetation records is possible on mountain summits. European botanists, fascinated by the limits of plant life, noted this potential more than a century ago (Fig. 1) ${ }^{18}$ : “On the basis of a comprehensive description of locations, it will not be difficult to verify my species lists, and an increase or decrease of species richness in the future will be possible to detect with high certainty" (Josias Braun-Blanquet in 1913, translated from 31, p. 329). The foresight and the data they gathered on mountain summits gives us the opportunity to study the effect of accelerated warming on plant species richness. Thus, summits are optimal for resurveys of species occurrences and for detecting change in plant species richness over time, even when the first surveys were carried out prior to the GPS era. In this study, 302 summits with historical vegetation records were resurveyed between one and five times, resulting in a total of $n=698$ surveys. All vegetation surveys were conducted in summer. For each survey, all plant species occurring on the summit (generally delineated by the uppermost 10 meters of elevation) ${ }^{32}$ were noted. Vegetation surveys were compared for each summit. Species names were standardized to the nomenclature of Flora Europaea (or local floras for species absent in the Flora, see online Supplementary Information at www.nature.com/nature).

Environmental data. For each summit, mean monthly temperature and precipitation were calculated following the established change factor methodology ${ }^{33}$, which combines statistical downscaling with temporal trend analyses. First, temporal data available from CRU TS 3.23 (0.5 degree resolution, 1901-2015) ${ }^{34}$ and the European Gridded Monthly Temperature (0.5 degree resolution, 1765-2000) ${ }^{34}$ were statistically related to the higher spatial resolution of WorldClim monthly mean climatic grids (30 arc-second resolution) for the overlapping period of 1950 to 2000 using the change factor method ${ }^{33}$. We assumed that anomalies (cf. mean value over the period 1950-2000 of the coarse-grained climatic conditions minus the climatic conditions within each smaller pixel of WorldClim) computed for the overlapping period (1950-2000) remain the same prior to 1950 and after 2000. Second, elevational differences 
between summits and the mean elevation of the corresponding WorldClim digital elevation model were included as an additional correction term $\left(-0.006^{\circ} \mathrm{C} \times \Delta\right.$ elevation in $\left.\mathrm{m}\right)$ for mean temperature data. By combining the two corrections, temporal trends available from the 0.5 degree resolution temporal data were corrected for i) differences originating from scale and climate model and ii) the precise elevation of the summit (temperature only). While we consider the resulting temporal trends for the temperature data to be reliable due to the generally higher spatial and temporal autocorrelation and a higher correlation with elevation, the precipitation data do not show a systematic change with elevation and are less predictable over small spatial distances ${ }^{36}$ and, therefore, need to be interpreted more cautiously. Environmental variables were included in the models after calculating temporal changes (see end of the Methods section). Consequently, environmental variables are unbiased by weaknesses in the spatial interpolations. For temperature and precipitation, time series from CRU TS 3.23 (1901-2015) and the European Gridded Monthly Temperature (1765-2000) were combined to match the study period (1880-2016) by taking the mean per grid cell for the overlapping years (Spearman $r=0.97$ for the overlapping period 1901-2000). As none of the two data sources extends to 2016, climate values for 2015 were taken again for 2016 for the 19 affected summits. Further, historical nitrogen deposition data (NHx and NOx modeled from 1850-2010) were extracted from the European Fluxes Database (www.europefluxdata.eu) and interpolated for the missing five years (2011-2016). The data originate from the global chemistry Transport Model version 5 (TM5, annual data with a $0.25^{\circ}$ lat/long resolution) ${ }^{37}$. Data handling and all subsequent analyses were conducted in R version 3.3.1.

\section{Statistical analyses.}

The velocity of species richness changes: Species richness (SR) on mountain summits was analyzed for its change with time (t: year of record) across all summits by implementing a generalized linear mixed effects model (GLMM) with a Poisson family error distribution (SR $\sim \mathrm{t}$ ) and a random effect (intercept) of mountains to account for repeated samples (GLMM 1 in Extended Data Table 1, mixed effects models always built with R package Ime4 version 
1.1-12) ${ }^{39}$. Further, we ran the models including random effects (intercept) of region (mountains nested in region; GLMM 2 in Extended Data Table 1) and observation ID (to account for over dispersion; see reference 40; GLMM 3 in Extended Data Table 1). All models provided qualitatively equivalent results (Extended Data Table 1).

We repeated all GLMMs allowing a breakpoint (bp) in the relationship between species richness and time by fitting independent slope coefficients for the time period prior and after the breakpoint (SR $\sim$ ifelse $(\mathrm{t}<\mathrm{bp}$, bp - t, 0) + ifelse $(\mathrm{t}<\mathrm{bp}, 0, \mathrm{t}-\mathrm{bp})+$ random structure). The breakpoint was fitted independently by minimizing the model deviance (Extended Data Table 1). It is likely that the real breakpoint (cf. the onset) of the acceleration trend in the increase in plant species richness happened slightly later than the estimated breakpoint suggested by this particular analysis. Indeed, the estimated breakpoint approximates the timing of change as the year between two sequential surveys and thus mechanistically moves every change temporally towards the median of the time series.

Acceleration of species richness changes: The potential acceleration in the average velocity of species richness changes on mountain summits between 1871 and 2016 was tested by means of a linear mixed effects model (LMM) with a Gaussian family error distribution $\left(\Delta \mathrm{SR} / \Delta \mathrm{t} \sim \mathrm{t}_{\mathrm{MP}}\right.$ ). With the model, we analyzed the rate of change in species richness over time (midpoint year between two surveys $\left.\mathrm{t}_{\mathrm{MP}}=\left(\mathrm{t}_{1}+\mathrm{t}_{2}\right) / 2\right)$. The dependent variable $\Delta \mathrm{SR} / \Delta \mathrm{t}$ was calculated based on the difference in species richness and the difference between years of observation of two consecutive surveys on the same summit $\left(\left(\mathrm{SR}_{\mathrm{t} 2}-\mathrm{SR}_{\mathrm{t} 1}\right) /\left(\mathrm{t}_{2}-\mathrm{t}_{1}\right)\right)$. A random effect (intercept) of mountain was included to account for repeated samples. We also ran the model including a random effect (intercept) of mountain nested within region but found qualitatively similar results (Extended Data Table 2). Mathematically, $\Delta \mathrm{SR} / \Delta \mathrm{t}$ is independent from richness on the summits as well as from time elapsed between sequential visits on the summit. However, more species-rich systems seemed to be associated with higher rates of changes, as indicated by a significant positive effect if baseline (cf. the first survey) species richness of the summit was included as an explanatory variable in the fixed component of the 
LMM (Extended Data Table 2). We also tested if there was an effect of the number of years between two consecutive surveys on $\Delta \mathrm{SR} / \Delta \mathrm{t}$, as a longer period between surveys might mask short-term fluctuations, but this effect was not significant (Extended Data Table 2).

A linear increase in the rate of change with time $\left(\Delta \mathrm{SR} / \Delta \mathrm{t} \sim \mathrm{t}_{\mathrm{MP}}\right)$ corresponds to an accelerated richness increase. As Fig 2 and Fig 3 indicate a non-linearity in the relationship, we also run all models allowing a breakpoint in the relationship between the rate of change and the time between surveys (Extended Data Table 2).

In the raw data, the average rate of species richness increase per summit was found to be much higher in the last decade (2007-2016; +2.9 species) compared to fifty years earlier (1957-1966, +1.1 species). When the slopes are averaged across all summits with an observation prior and after a respective year, inversely weighted by the number of years between observations (to account for temporal resolution, as a longer period between surveys might mask short-term fluctuations), the differences become even more apparent $(+5.4$ species in the last decade as opposed to +1.1 species per decade fifty years earlier).

Visualization of temporal changes in richness: The average richness change per year $(\Delta \mathrm{SR} / \Delta \mathrm{t}$ $\left.=\left(\mathrm{SR}_{\mathrm{t} 2}-\mathrm{SR}_{\mathrm{t} 1}\right) /\left(\mathrm{t}_{2}-\mathrm{t}_{1}\right)\right)$ across all summits was calculated (see Extended Data Figure 1a for method). Fig. 3 displays how the average in $\Delta \mathrm{SR} / \Delta \mathrm{t}$ across all summits changed over time. As values for $\Delta \mathrm{SR} / \Delta \mathrm{t}$ originating from summits with a higher temporal sampling density better represent the instant rate of change for that specific year (t), we inversely weighted the calculated values for $\Delta \mathrm{SR} / \Delta \mathrm{t}$ by the difference in years between observations $\left(\mathrm{t}_{2}-\mathrm{t}_{1}\right)$ to account for temporal resolution.

The changes in species richness per year $(\Delta \mathrm{SR} / \Delta \mathrm{t})$ accumulated over time and result in an absolute change in species richness (Extended Data Figure 1b). These absolute changes in species richness are visualized for each region in Fig. 2 (black line). In order to also visualize variability within regions, confidence intervals were calculated based on the standard deviation of richness change among summits in a region (see Extended Data Figure $1 \mathrm{c}$ and $1 \mathrm{~d}$ and related figure caption). 
Importance of environmental drivers: The average velocity of species richness changes $(\Delta \mathrm{SR} / \Delta \mathrm{t})$ was related to the change in mean annual temperature $(\Delta \mathrm{T} / \Delta \mathrm{t} ; \mathrm{T}=$ temperature $)$ and precipitation $(\Delta \mathrm{P} / \Delta \mathrm{t} ; \mathrm{P}=$ precipitation) for the same period (see below for further details), as well as to the accumulated nitrogen deposition (Naccum; $\mathrm{N}=$ nitrogen, details explained below) across all summits, by implementing LMMs with a Gaussian family error distribution that included each of the three potential explanatory variables (different rows in Extended Data Table 3, model formula can be seen in table caption). Variable performance was compared using the corrected version (for small sample size) of the Aikaike Information Criteria $\left(\mathrm{AICc}^{41}\right)$. All LMMs consistently detected a clear positive relationship between species richness changes and temperature changes while a slightly weaker positive relationship with precipitation changes was also detected. Particularly the relationship with temperature changes is surprisingly strong considering that climate models are built on longterm air temperature measurements at two meters above ground in climate stations that are mainly located in valleys and can only approximate changes in growth conditions for summits species. No relationship with the accumulated nitrogen deposition was detected across Europe (Extended Data Table 3).

The explanatory variables $\Delta \mathrm{T} / \Delta \mathrm{t}$ and $\Delta \mathrm{P} / \Delta \mathrm{t}$ were calculated as the mean change per year (e.g. $\Delta \mathrm{T} / \Delta \mathrm{t}=\mathrm{T}_{\mathrm{t} 2}-\mathrm{T}_{\mathrm{t} 1} / \mathrm{t}_{2}-\mathrm{t}_{1}$ ). Climate variables like temperature and precipitation are usually integrated over longer time periods to level out short-term fluctuations. As we were interested in the effect of such shorter-term fluctuations, we systematically tested which periods would provide the best fit within our LMM framework (1-30 years). Besides mean annual temperature and precipitation, we further tested alternative measurements of the climate variables. If species’ ranges are limited primarily by growing season temperatures, we would expect spring and summer warming to best explain temporal changes in species richness. Alternatively, if many alpine species are limited not by growing season temperature, but rather by climatic extremes, winter temperatures or precipitation might be more important in determining which species can survive in a given location. We therefore systematically 
pre-analyzed temperature and precipitation variables by testing for the effect of winter precipitation (Dec-Feb) and of snow accumulation (precipitation in months with a mean temperature below freezing).

Further, nitrogen from deposition may accumulate in the soil, particularly in high elevation systems with limited resource cycling ${ }^{42,43}$. In our data, nitrogen deposition has declined sharply in recent decades ${ }^{36}$, although its accumulated effect may still influence community dynamics ${ }^{43}$. We thus calculated accumulated deposition of both $\mathrm{NH}_{4}$ and $\mathrm{NO}_{3}$ since 1850 for each vegetation survey.

The systematic test of different variables and time periods (Extended Data Table 4) identified annual summer temperature (15-year mean), annual precipitation (1-year mean) and $\mathrm{NO}_{3}$ (referred to as $\mathrm{N}_{\mathrm{accum}}$ ) as the most suitable predictors, and these variables were then used in all subsequent analyses. As this type of variable selection biases analyses towards significant relationships, all analyses were repeated with mean annual values (10-year mean), resulting in qualitatively similar results. Model residuals were visually checked for temporal autocorrelation signal without any sign of a temporal trend in the residuals.

Time-lags in richness change: Biotic responses may show a delayed response to climate change ${ }^{17,24}$. Therefore, observed species richness on a mountain summit at given point in time could reflect climatic conditions from several years earlier, as species may need considerable time to spread and establish (cf. migration and establishment lags). A systematic time-lag was therefore implemented between our observation and the climate period used to relate the average velocity of species richness changes with changes in climatic conditions and tested for a potential increase in explanatory power (tested lags 5 and 10 years; Extended Data Table 5). Final results are presented without time-lags, because including them did not increase the power in our analyses to explain the average velocity of species richness changes.

An alternative approach to analyzing the average velocity of species richness changes $(\Delta \mathrm{SR} / \Delta \mathrm{t})$ with rates of change in environmental predictors $(\Delta \mathrm{T} / \Delta \mathrm{t} ; \Delta \mathrm{P} / \Delta \mathrm{t}$, see Extended Data Table 3$)$ is to directly relate species richness changes $(\Delta \mathrm{SR})$ to changes in environmental 
variables over the same time period $(\Delta \mathrm{T} ; \Delta \mathrm{P})$. This approach is more intuitive (and closer to the data) but ignores differences in time between sampling events. Analyses with this approach yielded results qualitatively similar to the results of the main analysis (Extended Data Table 3), with the exception that the effect of precipitation changes was not significant (Extended Data Table 6).

\section{Trait based analyses.}

Differing trait signal in colonizing species: Changes in plant life strategies as well as dispersal constrains would be indicated by a systematic difference in indicative traits. We thus compared specific leaf area (SLA) ${ }^{45}$, plant height ${ }^{45}$ as well as seed mass ${ }^{45}$ between colonizing species as well as species in the resident community in a LMM framework setting resurvey as a random effect. To test for the colonization and establishment, within the recipient community, of warmth tolerating species from lower elevations, we used Landolt species indicator values for temperature ${ }^{45}$. Temperature indicator values ${ }^{45}$ were available for $91 \%$ of the observations. For 364 resurveys (altogether 20583 observations for 871 species) direct comparisons of plant trait values of species in a resurvey that were newly established colonizers with those species that had been present already in the previous survey (recipient community) indicate significantly increased SLA $(\mathrm{p}<0.01)$ and plant height $(\mathrm{p}<0.001)$ of successful colonizers but no significant difference in seed mass $(\mathrm{p}=0.053)$. Colonizers are more adapted to warmer climates than species of the resident communities $(\mathrm{p}<0.001$; Extended Data Table 7).

\section{Data reliability}

Sampling intensity: Our analysis of the rate of change is relatively robust with respect to different sampling periods. The increasing sampling intensity over time (Fig. 1) helped to reliably quantify the rates of change in later time periods and thus to support our conclusion on an acceleration in richness change. Consistent continent-wide and short-term fluctuations in species richness that might have occurred in the early 20th century would likely go 
undetected due to the lower data availability in the early 20th century of our time series data, but long-term trends would be well visible. We thus have no evidence that the unbalanced sampling effort over time and different sampling intervals hide unobserved fluctuations in early periods. In line with this, the summits for which we have a high number of repeated surveys show little short-term fluctuations but confirm the detected steady increase of richness over time and an acceleration in recent years ${ }^{16}$.

Observer errors: Previous studies explicitly addressing observer errors of summit resurveys, have demonstrated a reliable quantification for vegetation change over long time periods ${ }^{32}$. Many of the early records have been collected by expert botanists with a scientific interest in long-term changes and the explicit aim to allow a later resurvey. To further reduce potential sampling and observer errors, recent records were done without knowledge of the past species lists, because surveyors who know the historical species composition have a higher chance of finding certain species again. Approximately $15 \%$ of all summits of this dataset have species records collected in the 1980s and 1990s (partly they were even done by the same people). Even if these early re-surveyors also considered the above methodological issues, we cannot rule out that the observer effort of the early re-surveyors was higher than the historical one. However, we are sure that our recent observer effort did not exceed that of the early resurveyors during the 1980s and 1990s. Given this, the clear signal that most of the increase in species richness occurred after 1980s/1990s is a strong indication that a possible increase in observer effort, if present, is only responsible for a limited amount of the increase in species richness. We are, thus, confident, that observer errors did not systematically influence our analyses.

\section{Method references}

31. Braun, J. Die Vegetationsverhältnisse der Schneestufe in den Rätisch-Lepontischen Alpen. Ein Bild des Pflanzenlebens an seinen äußersten Grenzen. Neue Denkschr. Schweiz. Naturf. Ges. 48, 1-347 (1913). 
32. Burg, S., Rixen, C,. Stöckli, V. \& Wipf, S. Observation bias and its causes in botanical surveys on high-alpine summits. J. Veg. Sci. 26, 191-200 (2015).

33. Anandhi, A. et al. Examination of change factor methodologies or climate impact assessment. Water Resour. Res. 47, W03501 (2011).

34. Harris, I., Jones, P.D., Osborn, T.J. \& Lister, D.H. Updated high-resolution grids of monthly climatic observations - the CRU TS3.10 Dataset. Int. J. Climatol. 34, 623-642 (2014).

35. Casty, C., Raible, C.C., Stocker, T.F., Wanner, H.\& Luterbacher J. European Gridded Monthly Temperature, Precipitation and 500hPa Reconstructions. IGBP PAGES/World Data Center for Paleoclimatology Data Contribution Series \# 2008-023. NOAA/NCDC Paleoclimatology Program, Boulder CO, USA (2008).

36. Daly, C., Neilson, R.P. \& Phillips, D.L. A statistical topographic model for mapping climatological precipitation over mountainous terrain. J. Appl. Meteor. 33, 140-158 (1994).

37. Huijnen, V. et al. The global chemistry transport model TM5: description and evaluation of the tropospheric chemistry version 3.0. Geosci. Model Dev. 3, 445-473 (2010).

38. R Core Team, R: A language and environment for statistical computing. R Foundation for Statistical Computing, Vienna, Austria (2016).

39. Bates, D, Maechler, M., Bolker, B. \& Walker S. Fitting linear mixed-effects models using lme4. J. Stat. Softw. 67, 1-48 (2015).

40. Harrison, X.A. Using observation-level random effects to model overdispersion in count data in ecology and evolution. PeerJ 2, e616 (2014).

41. Burnham, K.P. \& Anderson, D.R. Model selection and multimodel inference: A practical information-theoretic approach (2nd ed.). New York: Springer (2002).

42. Burns, D.A. The effects of atmospheric nitrogen deposition in the Rocky Mountains of Colorado and southern Wyoming, USA — a critical review. Environ. Pollut. 127, 257-269 (2004).

43. Körner, C. Mountain ecosystems in a changing environment. Ecomont 6, 71-77 (2014). 
627

628
44. Bobbink, R. et al. Global assessment of nitrogen deposition effects on terrestrial plant diversity: a synthesis. Ecol. Appl. 20, 30-59 (2010).

45. Kleyer, M. et al. The LEDA Traitbase: A database of life-history traits of Northwest European flora. Journal of Ecology 96, 1266-1274 (2008).

46. Landolt, E. et al. Flora indicativa. Haupt Verlag, Bern (2010). 
Extended Data Table 1 | Results of generalized linear mixed effect models (Poisson family error distribution), showing an increase in species richness with time (richness $\sim$ year of record) when different random error structures are applied. The lower panel included a breakpoint in the relationship between rate of richness change and time. The breakpoint was fitted independently by minimizing model deviance and was estimated around the year 1970 .

All models are based on 698 observations. Significant effects are indicated by asterisks $\left({ }^{*} \mathrm{p}<0.05,{ }^{* *} \mathrm{p}<0.01,{ }^{* * *} \mathrm{p}<0.001\right)$. "GLMM" = Generalized linear mixed-effects model, "GLM"= Generalized linear model, "BPGLMM"= Generalized linear mixed-effects breakpoint model,“ID”= Observation ID.

\begin{tabular}{lllllrr}
\hline \multicolumn{2}{l}{ Fixed effect (coefficients \pm std. error) } & \multicolumn{3}{l}{ Random effects (std. deviations) } \\
\hline Model & Intercept & Year of record & Mountain & Region:Mountain & ID & AICc \\
\hline GLMM 1 & $-5.78 \pm 0.35^{* * *}$ & $0.004 \pm 0.0002^{* * *}$ & 0.97 & - & - & 5785 \\
GLMM 2 & $-5.78 \pm 0.35^{* * *}$ & $0.004 \pm 0.0002^{* * *}$ & 0.86 & 0.41 & - & 5787 \\
GLMM 3 & $-7.33 \pm 0.58^{* * *}$ & $0.005 \pm 0.0003^{* * *}$ & 0.47 & 0.84 & 0.23 & 5596 \\
GLM & $-7.52 \pm 0.33^{* * *}$ & $0.006 \pm 0.0002^{* * *}$ & - & - & - & 18299 \\
\hline \multicolumn{7}{c}{ Model } \\
\hline
\end{tabular}

Extended Data Table 2 | Results of linear mixed effects models (Gaussian family error distribution) showing an acceleration of the increase in species richness over time $(\Delta S R / \Delta t \sim t)$, where different random-effects structures are implemented (see Random effects below). Baseline richness of the summit and the number of years between two consecutive observations (Period) were included as additional explanatory variables. The lower panel further included a breakpoint in the relationship between rate of richness change and time. The breakpoint was fitted independently by minimizing model deviance and was estimated for the year 1971. All models were based on 396 observations (comparison of survey and resurveys). Significant effects are indicated by asterisks $\left({ }^{*} \mathrm{p}<0.05,{ }^{* *} \mathrm{p}<0.01,{ }^{* * *} \mathrm{p}<0.001\right)$. Note that models without random structure performed best.

\begin{tabular}{|c|c|c|c|c|c|c|c|}
\hline \multicolumn{4}{|c|}{ Fixed effect (coefficients \pm std. error) } & \multicolumn{4}{|c|}{ Random effect (std. deviations) } \\
\hline Intercept & Time & & Richness & Period & Mountain & Region: Mount. & AICC \\
\hline$-15.5 \pm 2.03 * * *$ & $0.008 \pm 0.001 * *$ & & - & - & $5.2 \times 10^{-8}$ & - & 570.3 \\
\hline$-15.5 \pm 2.06 * * *$ & $0.008 \pm 0.001 * *=$ & & - & - & $9.6 \times 10^{-8}$ & $4.8 \times 10^{-8}$ & 572.4 \\
\hline$-13.4 \pm 2.05^{* * *}$ & $0.007 \pm 0.001^{* * *}$ & & $0.004 \pm 0.001 * * *$ & - & $1.8 \times 10^{-8}$ & - & 562.6 \\
\hline$-11.7 \pm 4.77 *$ & $0.006 \pm 0.002 *$ & & $0.004 \pm 0.001^{* * *}$ & n.s. & $1.1 \times 10^{-7}$ & - & 576.0 \\
\hline$-13.4 \pm 2.05 * * *$ & $0.007 \pm 0.001^{* * *}$ & & $0.004 \pm 0.001^{* * *}$ & - & - & - & 530.7 \\
\hline Intercept & Time $<B P$ & Time $>B P$ & Richness & Period & Mountain & Region: Mount. & AICc \\
\hline $0.07 \pm 0.05$ & $0.002 \pm 0.003$ & $0.013 \pm 0.002 * * *$ & - & - & 0.0 & . & 571.3 \\
\hline $0.07 \pm 0.05$ & $0.002 \pm 0.003$ & $0.013 \pm 0.002^{* * *}$ & & & 0.0 & 0.0 & 573.3 \\
\hline $0.02 \pm 0.05$ & $0.0001 \pm 0.003$ & $0.011 \pm 0.002^{* * *}$ & $0.004 \pm 0.001^{* * *}$ & - & 0.0 & - & 568.5 \\
\hline$-0.09 \pm 0.14$ & $0.0004 \pm 0.004$ & $0.012 \pm 0.004^{* * *}$ & $0.004 \pm 0.001^{* * *}$ & n.s. & $1.1 \times 10^{-8}$ & - & 581.5 \\
\hline $0.02 \pm 0.05$ & $0.0001 \pm 0.003$ & $0.010 \pm 0.002^{* * *}$ & $0.004 \pm 0.001^{* * *}$ & - & - & - & 527.8 \\
\hline
\end{tabular}

Extended Data Table 3 | Results of linear mixed effects models (Gaussian family error) showing the relationship of the average velocity in species richness changes with the change in potential explanatory variables (temperature, precipitation, nitrogen deposition). Initial species richness on the summit was added as a further independent variable and indicated that species-rich systems showed a larger net change. The implemented model formula was $\operatorname{lmer}\left(\Delta \mathrm{SR} / \Delta \mathrm{t} \sim \Delta \mathrm{T} / \Delta \mathrm{t}+\Delta \mathrm{P} / \Delta \mathrm{t}+\mathrm{N}_{\text {accum }}+\right.$ richness + (1|mountain)). Variable performance was compared using AICc, which also sets the order of models, with the best one on top. In addition, significant results from tests using $F$ statistics are indicated by asterisks $\left({ }^{*} \mathrm{p}<0.05,{ }^{* *} \mathrm{p}<0.01,{ }^{* * *} \mathrm{p}<0.001\right)$. Rerunning the analyses after centering (subtracting the means) and scaling (dividing by standard deviations) the explanatory variables 
indicated a larger coefficient and thus stronger effect of temperature than that of precipitation $(\mathbf{\Delta S R} / \mathbf{\Delta t}$ $\sim 0.00( \pm 0.04)+0.39( \pm 0.05) \times \Delta \mathbf{T} / \Delta \mathbf{t}^{* * *}+0.21( \pm 0.04) \times \mathbf{\Delta} \mathbf{P} / \Delta \mathbf{t}^{* * *}+0.21( \pm 0.05) \times$ Richness $\left.\mathbf{s}^{* * *}\right)$. The analyses presented in the table were performed on a subset of the data, as no nitrogen data were available for the 7 summits of Svalbard. This subsetting resulted in 389 temporal comparisons (summits and revisits that resulted from 684 observations). We further repeated the full model combining all summits sampled over the same time period and falling in the same grid cell of climate data that were not downscaled (by taking the mean) to account for spatial autocorrelation. Results of this model were qualitatively similar $\left(\boldsymbol{\Delta} \mathbf{S R} / \Delta \mathbf{t} \sim-0.006( \pm 0.05)+9.5( \pm 1.1) \times \mathbf{\Delta T} / \Delta \mathbf{t}^{* * *+} 0.005\right.$ $( \pm 0.001) \times \Delta \mathbf{P} / \Delta \mathbf{t}^{* * *}-0.13( \pm 0.08) \times N_{\text {accum }}+0.005( \pm 0.05)$ x Richness***).

\begin{tabular}{lllllll}
\hline Intercept & $\boldsymbol{\Delta T} / \boldsymbol{\Delta t}$ & $\boldsymbol{\Delta P} / \boldsymbol{\Delta t}$ & $\boldsymbol{N}_{\text {accum }}$ & Richness & $\boldsymbol{A I C \boldsymbol { c }}$ & $\boldsymbol{A I C W t}$ \\
\hline $0.01 \pm 0.06$ & $9.6 \pm 1.1^{* * *}$ & $0.005 \pm 0.001^{* * *}$ & $-0.15 \pm 0.09$ & $0.004 \pm 0.001^{* * *}$ & 491.9 & 0.59 \\
$-0.06 \pm 0.04$ & $9.4 \pm 1.1^{* * *}$ & $0.005 \pm 0.001^{* * *}$ & - & $0.005 \pm 0.001^{* * *}$ & 492.7 & 0.41 \\
$0.03 \pm 0.06$ & $10.1 \pm 1.1^{* * *}$ & - & $-0.16 \pm 0.09$ & $0.004 \pm 0.001^{* * *}$ & 512.6 & 0.00 \\
$0.14 \pm 0.06^{*}$ & - & $0.004 \pm 0.001^{* * *}$ & $-0.06 \pm 0.10$ & $0.006 \pm 0.001^{* * *}$ & 560.4 & 0.00 \\
\hline
\end{tabular}

Extended Data Table 4 | Model evaluation for linear mixed effects models (Gaussian family error distribution) showing the relationship between average velocity of species richness changes and the change in potential explanatory variables (temperature, precipitation, nitrogen deposition). The implemented model formula was $\operatorname{lmer}(\Delta \mathrm{SR} / \Delta \mathrm{t} \sim$ $\Delta \mathrm{T} / \Delta \mathrm{t}+\Delta \mathrm{P} / \Delta \mathrm{t}+\mathrm{N}_{\mathrm{accum}}+$ richness $+(1 \mid$ mountain)). During each model run, the focal variable (left column) was exchanged while the remaining model was held constant. Variables were calculated as the mean value across a period prior to the survey (Period).

Temperature

\begin{tabular}{|c|c|c|c|c|}
\hline $\begin{array}{l}\text { Explanatory } \\
\text { variable }\end{array}$ & Period & AICc & $\Delta \mathrm{AICc}$ & AICc weights \\
\hline Summer temperature & 15 & 491.9 & 0.0 & 1.0 \\
\hline Annual temperature & 15 & 501.1 & 9.2 & 0.0 \\
\hline Spring temperature & 10 & 511.4 & 19.4 & 0.0 \\
\hline Annual temperature & 7 & 513.4 & 21.5 & 0.0 \\
\hline Spring temperature & 7 & 516.7 & 24.8 & 0.0 \\
\hline Summer temperature & 7 & 518.7 & 26.8 & 0.0 \\
\hline Annual temperature & 30 & 520.7 & 28.8 & 0.0 \\
\hline Annual temperature & 10 & 521.2 & 29.3 & 0.0 \\
\hline Spring temperature & 15 & 521.3 & 29.3 & 0.0 \\
\hline Annual temperature & 3 & 530.5 & 38.6 & 0.0 \\
\hline Spring temperature & 30 & 531.8 & 39.9 & 0.0 \\
\hline Summer temperature & 5 & 532.0 & 40.1 & 0.0 \\
\hline Summer temperature & 1 & 534.9 & 43.0 & 0.0 \\
\hline Summer temperature & 30 & 536.0 & 44.1 & 0.0 \\
\hline Annual temperature & 1 & 538.9 & 47.0 & 0.0 \\
\hline Annual temperature & 5 & 539.2 & 47.2 & 0.0 \\
\hline Summer temperature & 10 & 549.4 & 57.4 & 0.0 \\
\hline Spring temperature & 5 & 550.4 & 58.5 & 0.0 \\
\hline Summer temperature & 3 & 551.2 & 59.3 & 0.0 \\
\hline Spring temperature & 1 & 552.4 & 60.5 & 0.0 \\
\hline $\begin{array}{l}\text { Spring temperature } \\
\text { Precipitation }\end{array}$ & 3 & 555.7 & 63.8 & 0.0 \\
\hline $\begin{array}{l}\text { Explanatory } \\
\text { variable }\end{array}$ & Period & AICc & $\Delta \mathrm{AICc}$ & AICc weights \\
\hline Annual precipitation & 1 & 491.9 & 0.0 & 1.0 \\
\hline Winter precipitation & 15 & 504.3 & 12.4 & 0.0 \\
\hline Annual precipitation & 30 & 505.5 & 13.6 & 0.0 \\
\hline
\end{tabular}




\begin{tabular}{lllll} 
Winter precipitation & 1 & 508.1 & 16.2 & 0.0 \\
Snow precipitation & 30 & 508.4 & 16.5 & 0.0 \\
Winter precipitation & 5 & 508.6 & 16.7 & 0.0 \\
Summer precipitation & 30 & 508.9 & 17.0 & 0.0 \\
Snow precipitation & 7 & 509.4 & 17.5 & 0.0 \\
Summer precipitation & 5 & 510.7 & 18.8 & 0.0 \\
Winter precipitation & 30 & 510.9 & 19.0 & 0.0 \\
Snow precipitation & 1 & 511.9 & 20.0 & 0.0 \\
Snow precipitation & 10 & 512.3 & 20.3 & 0.0 \\
Annual precipitation & 15 & 513.0 & 21.1 & 0.0 \\
Snow precipitation & 15 & 513.1 & 21.1 & 0.0 \\
Annual precipitation & 5 & 513.1 & 21.2 & 0.0 \\
Winter precipitation & 3 & 513.4 & 21.5 & 0.0 \\
Annual precipitation & 10 & 513.7 & 21.8 & 0.0 \\
Summer precipitation & 10 & 513.7 & 21.8 & 0.0 \\
Summer precipitation & 15 & 513.7 & 21.8 & 0.0 \\
Summer precipitation & 7 & 514.2 & 22.2 & 0.0 \\
Winter precipitation & 10 & 514.3 & 22.4 & 0.0 \\
Summer precipitation & 3 & 514.3 & 22.4 & 0.0 \\
Snow precipitation & 5 & 514.4 & 22.5 & 0.0 \\
Snow precipitation & 3 & 514.5 & 22.6 & 0.0 \\
Annual precipitation & 3 & 514.6 & 22.7 & 0.0 \\
Summer precipitation & 1 & 514.6 & 22.7 & 0.0 \\
Annual precipitation & 7 & 514.6 & 22.7 & 0.0 \\
Winter precipitation & 7 & 514.7 & 22.8 & 0.0 \\
Nitrogen & & & & \\
\hline Explanatory & Period & AICc & $\mathbf{\Delta A I C c}$ & 0.41 \\
variable & & 491.9 & 0.0 & \\
\hline NO accumulation & - & 492.6 & 0.7 & \\
NH accumulation & - & & & \\
\hline & & & & \\
\hline
\end{tabular}


Extended Data Table 5 | Model evaluation for linear mixed effects models (Gaussian family error distribution) showing the relationship between average velocity of species richness changes and the change in potential explanatory variables (temperature, precipitation, nitrogen deposition). The implemented model formula was $\operatorname{lmer}(\Delta \mathrm{SR} / \Delta \mathrm{t} \sim$ $\Delta \mathrm{T} / \Delta \mathrm{t}+\Delta \mathrm{P} / \Delta \mathrm{t}+\mathrm{N}_{\text {accum }}+$ richness $+(1 \mid$ mountain)). Variables were calculated as the mean value across a period prior to the survey. During each model run, the focal variable implemented with a differing time-lag (time between the period and first survey; left column) was exchanged while the rest of the model was held constant.

Summer Temperature (15-year mean)

\begin{tabular}{lcll}
\hline Time lag & AICc & $\Delta$ AICc & AICc weights \\
\hline 0 & 501.1 & 0.0 & 1.0 \\
5 & 535.6 & 34.5 & 0.0 \\
10 & 550.2 & 49.1 & 0.0 \\
Annual precipitation (1-year mean) & & \\
\hline Time lag & AICc & $\Delta$ AICc & AICc weights \\
\hline 0 & 510.7 & 0.0 & 0.76 \\
5 & 514.1 & 3.4 & 0.14 \\
10 & 514.7 & 4.0 & 0.10 \\
Nitrogen accumulation & & & AICc weights \\
\hline Time lag & AICc & $\Delta$ AICc & 0.34 \\
\hline 0 & 491.9 & 0.0 & 0.33 \\
5 & 492.0 & 0.1 & 0.33 \\
10 & 492.0 & 0.1 & \\
\hline
\end{tabular}

Extended Data Table 6 | Linear mixed effects models (Gaussian family error distribution) showing the direct relationship between species richness changes and change in potential explanatory variables (temperature, precipitation, nitrogen deposition). Initial species richness on the summit was not added as a further independent variable, as it did not show significant effects in any of the models. The implemented model formula was $\operatorname{lm} \operatorname{ro}\left(\Delta \mathrm{SR} \sim \Delta \mathrm{T}+\Delta \mathrm{P}+\mathrm{N}_{\text {accum }}+\right.$ richness + (1|mountain)). Variable performance was compared using AICc, which also sets the order of models, with the best one on top. Additional significance tests using $\mathrm{F}$ statistics are indicated by asterisks $\left({ }^{*} \mathrm{p}<0.05,{ }^{* *} \mathrm{p}<0.01,{ }^{* * *} \mathrm{p}<0.001\right)$. Rerunning the analyses after centering (subtracting the means) and scaling (dividing by standard deviations) indicated a larger coefficient and thus stronger effect of temperature compared to that of precipitation $(\Delta \mathrm{SR} \sim 0.05( \pm 0.06)+0.25( \pm 0.05) \times \Delta \mathbf{T} * * *+0.05$ $( \pm 0.04)$ x $\left.\Delta \mathbf{P}-0.11( \pm 0.05) \times N_{\text {accum }}{ }^{*}\right)$.

\begin{tabular}{lllllll}
\hline Intercept & $\boldsymbol{\Delta T} / \boldsymbol{\Delta t}$ & $\boldsymbol{\Delta P} / \boldsymbol{\Delta t}$ & $\boldsymbol{N}_{\text {accum }}$ & Richness & $\boldsymbol{A I C \boldsymbol { C }}$ & $\boldsymbol{A I C W t}$ \\
\hline $7.6 \pm 1.6^{* * *}$ & $5.9 \pm 1.2^{* * *}$ & - & $-5.4 \pm 2.3^{*}$ & - & 3002.8 & 0.57 \\
$7.2 \pm 1.7^{* * *}$ & $6.3 \pm 1.3^{* * *}$ & $0.002 \pm 0.002$ & $-5.1 \pm 2.3^{*}$ & - & 3003.8 & 0.34 \\
$2.23 \pm 1.15$ & $8.25 \pm 1.92^{* * *}$ & $-0.011 \pm 0.010$ & - & - & 3006.5 & 0.09 \\
$11.8 \pm 1.48^{* * *}$ & - & $-0.001 \pm 0.002$ & $-3.7 \pm 2.4$ & - & 3023.2 & 0.00 \\
\hline
\end{tabular}

Extended Data Table 7 | Results of linear mixed effects models (Gaussian family error distribution) analyzing systematic trait differences between colonizing species and the resident community. Analyses are implemented for 258 mountains (750 species) with a random effect on mountain. Significant effects are indicated by asterisks $\left({ }^{*} \mathrm{p}<0.05,{ }^{* *} \mathrm{p}<0.01,{ }^{* * *} \mathrm{p}<0.001\right)$. Trait data were log transformed before analysis.

\begin{tabular}{|c|c|c|c|}
\hline Trait & Fixed effect (coe & fficients \pm std. error) & $\begin{array}{l}\text { Random effect } \\
\text { (std. deviations) }\end{array}$ \\
\hline Trait & Intercept & $\begin{array}{l}\text { Difference of colonizer relative to established } \\
\text { species }\end{array}$ & Mountain \\
\hline Plant height & $-1.92 \pm 0.02 * * *$ & $+0.20 \pm 0.02 * * *$ & 0.20 \\
\hline SLA & $2.870 \pm 0.006 * * *$ & $+0.021 \pm 0.008 * *$ & 0.04 \\
\hline
\end{tabular}




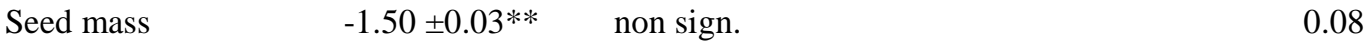

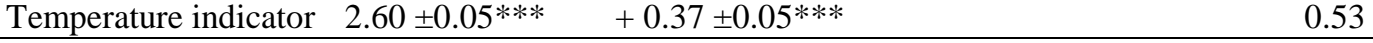

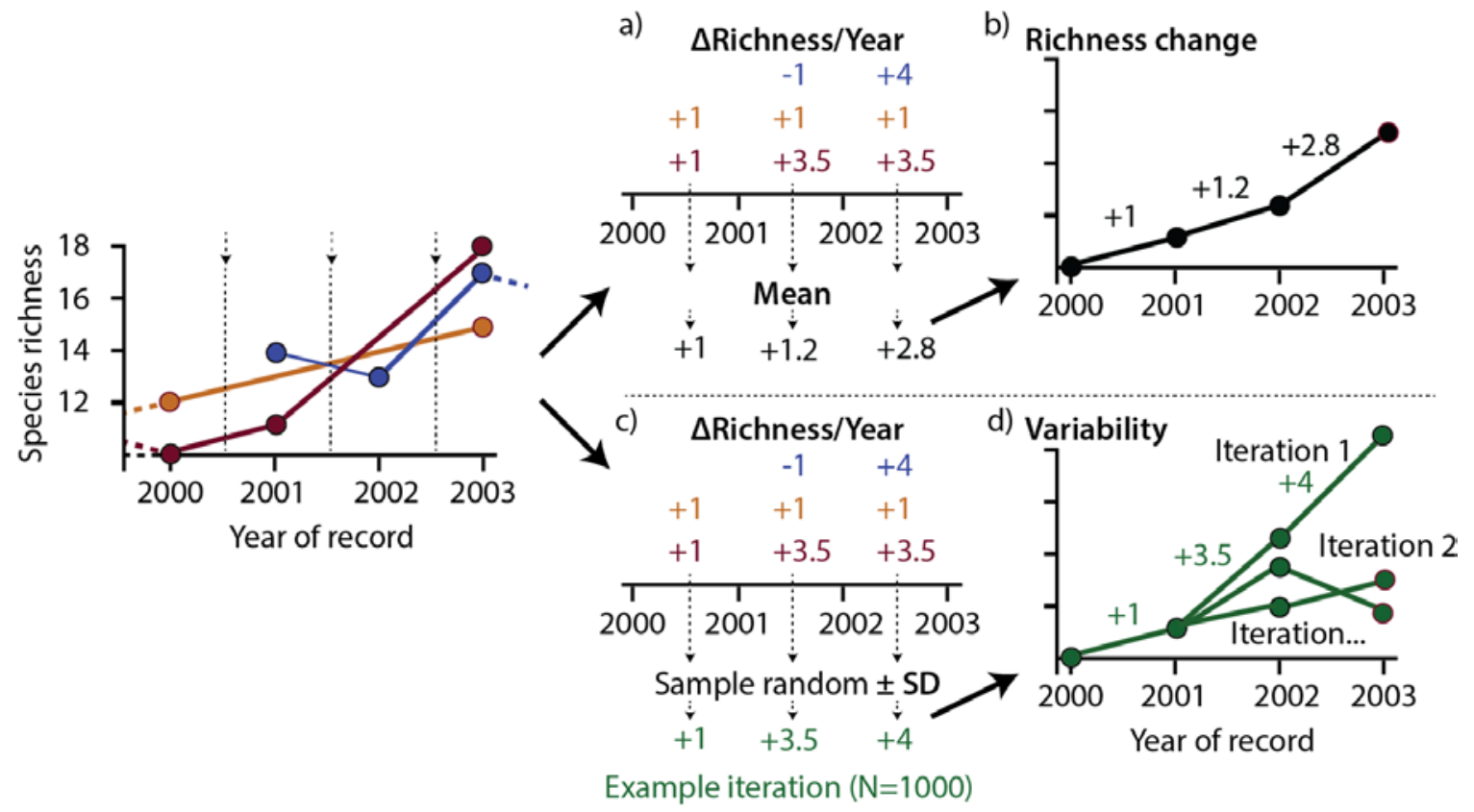

Extended Data Figure 1 | Conceptual figure showing the approach implemented in the

The mean richness change per year $\left(\Delta \mathrm{SR} / \Delta \mathrm{t}=\left(\mathrm{SR}_{\mathrm{t} 2}-\mathrm{SR}_{\mathrm{t} 1)} /\left(\mathrm{t}_{2}-\mathrm{t}_{1}\right)\right)\right.$ across all summits was taken (see Fig. 3 for result). b) The mean richness change per year accumulates with time to yield absolute changes in species richness (see black line in Fig. 2 for results). c) and d) variability in the absolute change in species richness was visualized by randomly sampling $\Delta \mathrm{SR}$ from all mountains available each year, but adding the standard deviation within a region and year. The displayed range in Fig. 2 illustrates the $5^{\text {th }}$ and $95^{\text {th }}$ percentiles of the resulting richness change values from 1000 runs (orange shading in Fig. 2). This approach reveals changes in variability among mountains over time while also showing overall variability for time steps where only a few summits were sampled (particularly in early time periods). 


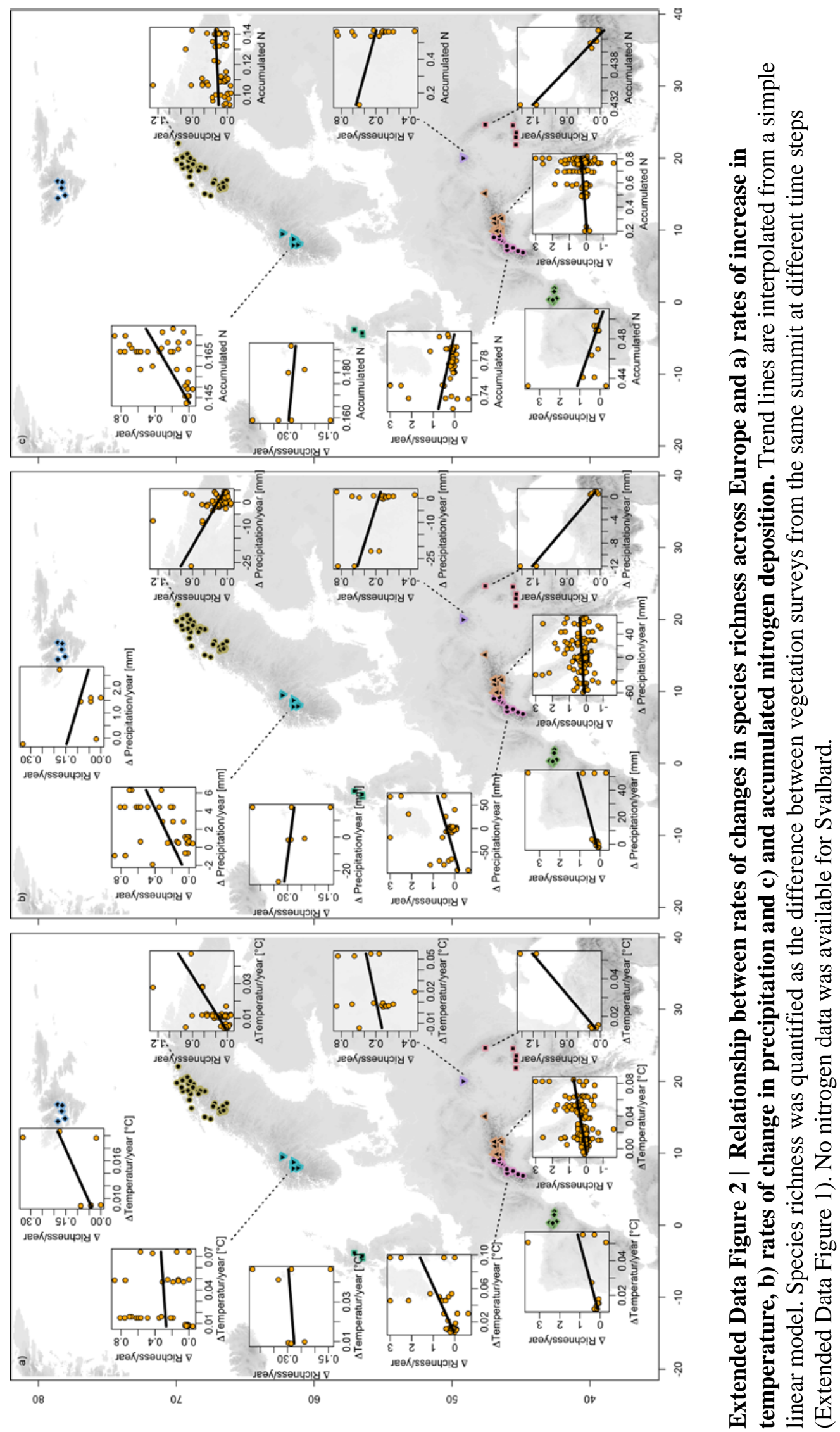


656

657 